\title{
GESTION DEL PATRIMONIO ARQUEOLOGICO EN PUERTO RICO: EL CASO DE LOS PARQUES NACIONALES ARQUEOLÓGICOS PRECOLONIALES Y LA CONSTRUCCIÓN ÉTNICA DE LOS "NEO -TAÍNO"
}

\author{
Gestão do Patrimônio Arqueológico em Porto Rico: O Caso dos Parques Nacionais \\ Arqueológicos Pré-coloniais e a Construção Étnica dos "Neo-Taíno"
}

Management of the Patrimonial Archaeological in Puerto Rico: The Case of the National Archaeological Parks Pre-colonial Ethnic and Construction of "Neo-Taíno"

\section{Cristina Burgos Otero ${ }^{1}$ Viviane Pouey Vidal $^{2}$}

\section{RESUMEN}

Este artículo tiene como objetivo abordar el contexto de los Parques Nacionales Arqueológicos Pre-coloniales de Puerto Rico, denotar las políticas actuales de gestión del patrimonio cultural en el país, así como demonstrar las disputas políticas entre el gobierno y los grupos indígenas. Comenta sobre el desarrollo de la práctica arqueológica, la construcción étnica de lo grupo "NeoTaíno" y sus reivindicaciones sobre los sitios arqueológicos, destacando la utilización de artefactos, monumentos y entierros en la preparación de su discurso étnico y la afirmación de su identidad indígena. Este estudio preliminar también reconoce y destaca la importancia de los estudios etnoarqueologícos para la identificación y comprensión del modo como el "Neo-Taíno" están construyendo y (re)construyendo su memoria indígena.

Palabras Clave: Construcción de Étnica; Neo-Taíno; Etnoarqueología y Patrimonio.

\section{RESUMO}

Este artigo visa abordar o contexto dos Parques Nacionais Arqueológicos Pré - coloniais de Porto Rico, denotando as atuais políticas de gestão do patrimônio cultural no país, bem como demonstrar as disputas políticas entre o governo e indígenas. Comenta ainda sobre o desenvolvimento da prática arqueológica, a construção étnica do grupo "Neo-Taíno" e suas reivindicações sobre os sítios arqueológicos, destacando a utilização de artefatos, monumentos e sepultamentos na elaboração do seu discurso étnico e na afirmação de sua identidade indígena. Este estudo preliminar também reconhece e enfatiza a importância de estudos etnoarqueológicos que possibilitem identificar e compreender como os "Neo-Taíno" estão construindo e (re) construindo a sua memória indígena.

Palavras-chave: Construção Étnica ; "Neo -Taíno", Etnoarqueología e Patrimônio.

\footnotetext{
${ }^{1}$ Antropóloga pela Universidade de Puerto Rico e Doutoranda em Arqueologia na UNICEN, Província de Buenos Aires,Olavarria.

${ }^{2}$ Msc em História área de concentração em Arqueologia pela PUC/RS e Doutoranda em Arqueologia na UNICEN, Província de Buenos Aires,Olavarria.
} 


\section{ABSTRACT}

This article aims to address the context of the National Parks Archaeological Pre-colonial Puerto Rico, denotes the current policies of cultural heritage management in the country, as well as demonstrates the political disputes between the government and the indigenous groups. Comment on the development of archeology, construction of ethnic groups as "Neo-Taino" and their claims about the archaeological sites, especially the use of objects, monuments and burials in the preparation of ethnicity speech and Indian identity assertion. This preliminary study also recognizes and emphasizes the importance of etnoarqueológicos studies for identifying and understanding as the "Neo-Taíno" are building and (re) constructing their indigenous memory.

Keywords: Construction Ethnic; Neo-Taíno; Ethnoarchaeology and Heritage.

\section{Introducción}

El tema del manejo del patrimonio arqueológico en Puerto Rico (en adelante PR) ha trascendido con una suerte de rezago por parte del desarrollo de las esferas académicas y en el desarrollo de la arqueología como disciplina. Las agencias tanto gubernamentales como federales encargadas de salvaguardar el patrimonio cultural se han caracterizado por una administración altamente criticada, que en los últimos años ha perdido fuerza y credibilidad. Por otra parte, la arqueología que se practica en la isla se comprende en un $90 \%$ por intervenciones sobre recursos arqueológicos en riesgo a ser impactados por proyectos de construcción. Esta situación provocó un descontento con el manejo de los recursos culturales en PR, generando una serie de críticas sobre la práctica de la arqueología en la isla (PAGÁN, 2001, 2004; PAGÁN Y RODRÍGUEZ, 2008; RODRÍGUEZ, 2007).

El desarrollo de la práctica arqueológica en Puerto Rico ha sido liderado, desde sus inicios a principios del siglo $\mathrm{XX}$, por arqueólogos estadounidenses, quienes se encargaron de construir la cronología del pasado precolombino de PR clasificándolo en categorías históricoculturales. El auge de los trabajos arqueológicos interrumpe la tarea de los etnohistoriadores, que para finales de siglo XIX y principios de siglo XX ya habían comenzado a documentar una reconstrucción del pasado histórico nacional (PAGÁN Y RODRÍGUEZ, 2008). El enfoque consolidado desde la década de los cincuenta por los trabajos de Irving Rouse y colaboradores, se aplica hasta la actualidad. De forma tal que el primer arqueólogo puertorriqueño -y el fundador 
del Instituto de Cultura Puertorriqueña (ICP)-, Ricardo Alegría enmarca su producción dentro de esta corriente.

En este contexto, todas estas circunstancias matizan la práctica arqueológica en PR. A ello se suma la situación sociopolítica que atraviesa la isla, en tanto Estado Libre Asociado, (Commonwealth) lo que influye directamente con el desarrollo de la arqueología. Por consiguiente, el panorama de la disciplina se ha visto afectado y/o condicionado por prácticas, narrativas y representaciones culturales de carácter colonial (RODRÍGUEZ, 2009; RODRÍGUEZ PAGÁN, 2008; PAGÁN, 2004); reflejado en la reivindicación de lo "taíno", es decir nuestro pasado indígena, en la construcción de una identidad nacional.

De este modo, se reproduce un discurso que simplifica la historia precolombina a la categoría "taíno", conocida por los relatos de los cronistas españoles como la población que habitaba la isla durante el periodo de la conquista y colonización española del siglo XV. Dicha categorización se construye en base a la generalización de esta población como arahuaco parlante, encausándola en una descripción sólita de una expresión monocultural. Sin embargo las investigaciones arqueológicas de la última década han arrojado luz sobre la composición cultural y social del Caribe insular que se caracterizó por ser un contexto multicultural desde sus ocupaciones iníciales (RODRÍGUEZ RAMOS, 2005a, 2007; WILSON, 1993; citado por: PAGAN Y RODRIGUEZ, 2008). En variadas ocasiones se ha evidenciado manifestaciones culturales que muestran la interacción circum-caribeña discutida por algunos autores (e.g. HOFMAN, BRIGHT, RODRÍGUEZ, 2010), es decir, la relación intercontinental e inter-isla con el Caribe insular. La pluralidad de los habitantes del Caribe insular se interpreta como producto de vínculos inter-sociales mediante relaciones macro-regionales con el área Istmo-Colombiana y regiones continentales adyacentes al Mar Caribe (RODRÍGUEZ, 2007 y 2010). Como resultado podemos apreciar que en la propuesta inicial se reduce una historia de 6.000 años de poblamiento de este territorio a una fracción de tiempo sucedida durante el periodo de contacto europeo. Ha sido labor de los organismos nacionales el de promover este discurso tanto en esferas educativa, profesional, como también en la turística. 


\section{La Gestión del Patrimonio}

El manejo del patrimonio en Puerto Rico depende tradicionalmente de tres esferas:1) la administración pública, 2) las organizaciones privadas y 3) la academia (e.g. toda institución universitaria tanto privada como pública que a nivel postsecundario lleve a cabo la práctica arqueológica- ya sea en su predio o como investigaciones anexas a algún programa de dicha unidad académica en PR). Con respecto al primer campo se presentan una serie de divergencias que han estructurado la trayectoria que actualmente comprenden lo que son las agencias estatal y federal. Algunos cambios organizativos que han moldeado dichas instituciones se remontan a sus inicios cuando la oficina federal pertenecía al organismo estatal, esta fue creada para responder a una oficina gubernamental; y más adelante fue separada y autonomizada. Actualmente trabaja como un departamento aparte. Como resultado, la jurisdicción de las agencias para la atención de los casos varía de acuerdo a la normativa. Además, con referencia a la representatividad de arqueólogos/as en estas agencias, en ocasiones es escasa, lo que limita la consideración de sugerencias profesionales y especializadas en el desarrollo de los planes de gestión y en la toma de decisiones de la conservación a fin con la variabilidad de los recursos arqueológicos.

\subsection{Organizaciones Encargadas del Manejo del Patrimonio Cultural en Puerto Rico}

Las instituciones y organizaciones gestoras del patrimonio en PR se han forjado bajo el paraguas de un marco legal, que tiene dos niveles, el estatal (Puerto Rico) y federal (Estados Unidos de Norteamérica). La tarea de manejo, que varía entre la función de la organización administrativa y la territorial dentro de las estructuras jurídicas (BALLART Y TRESSERRAS, 2007), se traduce en el contexto político de PR en federal, estatal y local. A nivel local solo los Municipios Autónomos se rigen por la normativa de los planes de ordenamiento territorial que igualmente responden a la Ley 170, según enmendada en el 1988, "Ley de Procedimiento Administrativo Uniforme del Estado Asociado de Puerto Rico". En virtud a esta ley, se regulan los permisos adjudicados por la Administración de Reglamentos y Permisos (ARPE), la cual se rige, además, por la reglamentación adscrita al Departamento de Arqueología y Etnohistoria del ICP. Dentro de este Departamento es en el Consejo de Arqueología Terrestre donde se otorgan los permisos que implican la aprobación o denegación de proyectos de construcción basados en 
informes de impacto de sitios arqueológicos (aunque nunca se derogan, más bien se detienen o aplazan los planes construcción de acuerdo al impacto que hayan recibidos los recursos arqueológicos al momento, para así establezca y el tiempo que requiera el trabajo arqueológico).

El marco legal a nivel federal se desprende inicialmente del National Historic Preservation Act de 1966, que en la Sección 106 regula las intervenciones de las agencias federales en propiedades históricas. Estas últimas son definidas como "cualquier distrito o sitio, edificio, estructura, artefacto, registro y/o restos prehistóricos o histórico, los cuales también elegibles para su inclusión en el Registro Nacional". De esta manera incluye los proyectos, actividades o programas con permisos, licencias o financiamiento federal, entre las cuales la Oficina Estatal de Conservación Histórica (en adelante $\mathrm{OECH}$ ) se especializa en la asesoría y evaluación del cumplimiento de la ley federal.

Esta oficina federal, dependiente del Servicio Forestal, se encarga de la protección y preservación de los complejos arquitectónicos y arqueológicos de valor histórico. Mediante el Plan Estatal de Conservación Histórica de Puerto Rico expide informes de reconocimientos de propiedades históricas y atiende las nominaciones del Registro Nacional de Lugares Históricos (adscrito a Washington DC, EEUU).

En referencia a la aplicación de las normativas correspondientes a las diferentes agencias involucradas en la protección del patrimonio, por su parte, la legislación federal (National Historic Preservation Act) Ley Nacional de Preservación Histórica expone que el gobierno local puede actuar como la agencia oficial bajo la Sección 106. Se ha comentado que su implementación en algunos casos ha sido perjudicial, ya que en la práctica no ha tenido en cuenta los lineamientos de "las agencias reguladoras nacionales ni considera diversos aspectos de índole social y cultural" (RODRÍGUEZ LÓPEZ, 2009), como tampoco a organizaciones, comunidades adyacentes a los sitios arqueológicos y Consulting parties (partes que deben ser consultadas, según la Sección 106 de ANCH: 36 CFR PART 800) para asegurar que los recursos culturales se tomen en cuenta en los proyectos de "planificación y desarrollo" (CARRILLO, 2007). Por tanto, se añaden otros factores como la comunicación insuficiente entre agencias, las tensiones internas entre miembros y líderes de las comunidades, generando conflictos y perpetuando una inestabilidad organizativa que produce una gestión fragmentada del patrimonio (WENBANSMITH, 1995). 
A escala autonómica se encuentra el Instituto de Cultura Puertorriqueña, organismo gubernamental fundado para el año 1955 respondiendo a la Ley 89 de julio del mismo año, conocida como la "Ley del Instituto de Cultura Puertorriqueña". En principio fomenta la preservación del patrimonio cultural, mediante la conservación, promoción, estimulo y divulgación de las diferentes esferas de la cultura puertorriqueña. Dentro del cual opera el Consejo de Arqueología Terrestre, como organismo autónomo -creado por la Ley 112 de Arqueología Terrestre, (1988)- pero dependiente en algunos requerimientos de la División de Arqueología y Etnohistoria del ICP (RODRÍGUEZ, 2007). El Consejo tiene como propósito la protección del patrimonio, asistiendo en las evaluaciones de Proyectos de Construcción que impactan yacimientos arqueológicos. Este organismo actúa, además, como única agencia reguladora de proyectos de investigación arqueológicos de Culural Resource Management (RODRÍGUEZ, 2007).

Este panorama del manejo de los recursos arqueológicos en PR ha dinamizado discusiones que exponen varias posturas frente a esta compleja situación. Por una parte Carrillo (2007) atribuye el problema al carácter estructural ocasionado por el desarrollo y actual división de las funciones de conservación patrimonial como resultado de este tipo de funcionamiento multi-agencial. Mientras que Yasha Rodríguez (2007), dirigió una investigación donde examina la protección del patrimonio arqueológico, refiriéndose a la destrucción de los sitios, y el efecto de la poca documentación que existe sobre estos. También exploró el marco legal, reconociendo igualmente las limitaciones de dichas normativas sobre el desempeño de la arqueología en Puerto Rico, subordinada a la arqueología de salvamento o al CRM.

Como trabajo experimental integró a grupos de la comunidad local donde llevo a cabo su proyecto de investigación en la participación de jornadas de campo arqueológicas. Como resultado obtuvo una respuesta favorable de los participantes, concluyendo en que una mayor concientización de la comunidad incrementarían las posibilidades de preservación del patrimonio arqueológico en las localidades adyacentes a Muntaner, en el municipio de Jayuya, PR. Estas respuestas a la aquejada situación del manejo del patrimonio en PR coinciden en señalar la ineficiencia de la administración pública, combinada al cuerpo legal en que se enmarca, como mayores eslabones de la cadena operativa que se muestra fragmentada en su insuficiente labor protectora. 
Con referencia al campo disciplinar, a pesar de que el año pasado se formalizó el primer posgrado en Arqueología de la isla, ha sido afectado por la ausencia de un ámbito académico desarrollado en PR, por consiguiente la formación de arqueólogos/as se ha efectuado fuera del país. De este modo la participación de la esfera académica en el manejo de los recursos arqueológicos depende de las aportaciones que los profesionales preparados en universidades foráneas puedan contribuir con sus respectivas investigaciones. Lo que genera una separación entre el desenvolvimiento investigativo tanto arqueológico como interdisciplinar con la capacidad de intervenir en estos procesos sobre el manejo y la protección del patrimonio arqueológico.

Por consiguiente en la práctica arqueológica se presentan una serie de problemas referentes a la conservación, y la disposición de materiales que ha desembocado en la remoción del material arqueológico del país, encausados en una precariedad del proceso de gestión. Como resultado se ponen en cuestión la implementación de los criterios de preservación, la regularidad del mantenimiento y la calidad de diálogo entre las agencias reguladoras, los arqueólogos, y especialistas en conservación de los recursos arqueológicos.

\section{Grupos Indígenas en Puerto Rico y La Etnoarqueología}

La Etnoarqueología incluye el campo de estudio de la producción, tipología, distribución, consumo, y descarte de la cultura material, con especial referencia a los mecanismos que relacionan variabilidad y la variación al contexto sociocultural y a la inferencia de los mecanismos de procesos del cambio cultura (DAVID, 1992 apud POLITIS, 2002: 67).

En las últimas décadas algunos sectores de la sociedad de Puerto Rico han mostrado su interés sobre el manejo del patrimonio. Entre estos se encuentran una serie de agrupaciones con el fin común de reclamar el legado del pasado precolonial de la isla. Las manifestaciones de estas organizaciones, mencionadas como "neo-taínos" (RODRÍGUEZ, 2007; PAGÁN Y RODRÍGUEZ, 2008) que demandan la participación y la pertenencia de los bienes culturales, incluida la repatriación de enterramientos ha detonado choques entre el mundo académico y estos grupos de interés. Estas controversias constituyen un factor fluctuante en el manejo del patrimonio arqueológico (HODDER, 1999). El caso de Puerto Rico ha tenido una serie de críticas, por parte de los etnohistoriadores (HASLIP VIERA, 2006; DE LA LUZ, 2006), 
generadas en respuesta a exposiciones de grupos, como la "Taíno Nation", en congresos de Arqueología (SAA 2004, entre otros transcurridos en EEUU).

Estas polémicas dan origen a interpretaciones con respecto a los procesos de construcción de identidades como resultado de discusiones relativas a la ley de repatriación conocida como "Native American Grave Protection and Repatriaton Act" (NAGPRA) vigente en EEUU. El resultado de los debates sobre estas y otras temáticas relacionadas a los reclamos de organizaciones indígenas han motivado cambios sobre la metodología y la práctica de la arqueología (SMITH, 2004). En virtud de todo lo expuesto, la práctica arqueológica en PR está guiada por una política pública, que no implica un diálogo entre los desarrollos académicos vinculados con el estudio y preservación del patrimonio arqueológico (tanto vinculados a los desarrollos realizados por cientístas sociales - e.g. arqueología - como técnicos - e.g. conservadores -) y la administración pública.

Lo que se interesa dilucidar y conocer a partir de esta investigación es si las limitaciones de la práctica arqueológica, promovida por las agencias responsables del manejo de los recursos arqueológicos, responde a una limitación propia del marco legal, tanto nacional como federal, para la administración y manejo del patrimonio, y/o si se debe al ejercicio discrecional que estas entidades gubernamentales hacen de dichas normativas. En este contexto, se comprende la necesidad de futuros estudios etnoarqueologícos con grupos que se "autoreconocen" como descendientes directos de los indígenas "Taíno" precoloniales, o sea, visto por la sociedad como los "Neo-Taínos". Las metodologías de la etnoarqueología permitirán conocer y comprender una mayor dimensión de la construcción simbólica y étnica de estos grupos, bien como su relación de pertenencia con el espacio arqueológico que reivindican al gobierno.

Actualmente a pesar de la importancia de las investigaciones etnoarqueologícas poco se ha realizado en PR, específicamente en relación a los grupos "Neo -Taíno", hasta el momento nada se a publicado con este enfoque. De ese modo, en este artículo buscamos conocer más sobre la etnoarqueología con el objetivo de utilizar sus herramientas teóricas y metodológicas a lo largo de los trabajos que están siendo realizados con los indígenas sobre el manejo y preservación del Patrimonio Arqueológico de estos Parques Nacionales. Teniendo en consideración que los actuales Taínos establecieran una relación de pertenencia con este patrimonio y fortifican sus discursos sobre la herencia de sus ancestros en el área. Así buscan en el paisaje arqueológico elementos culturales y simbólicos para integrar a su discurso étnico y político durante el proceso 
de reivindicación de sus derechos sobre la tierra de los parques. En las siguientes imágenes (1 y 2) es posible observar miembros de lo grupo "Neo - Taíno" ocupando los Parques Nacionales de Puerto Rico incurriendo en manifestaciones culturales y reclamando sus derechos sobre la tierra.

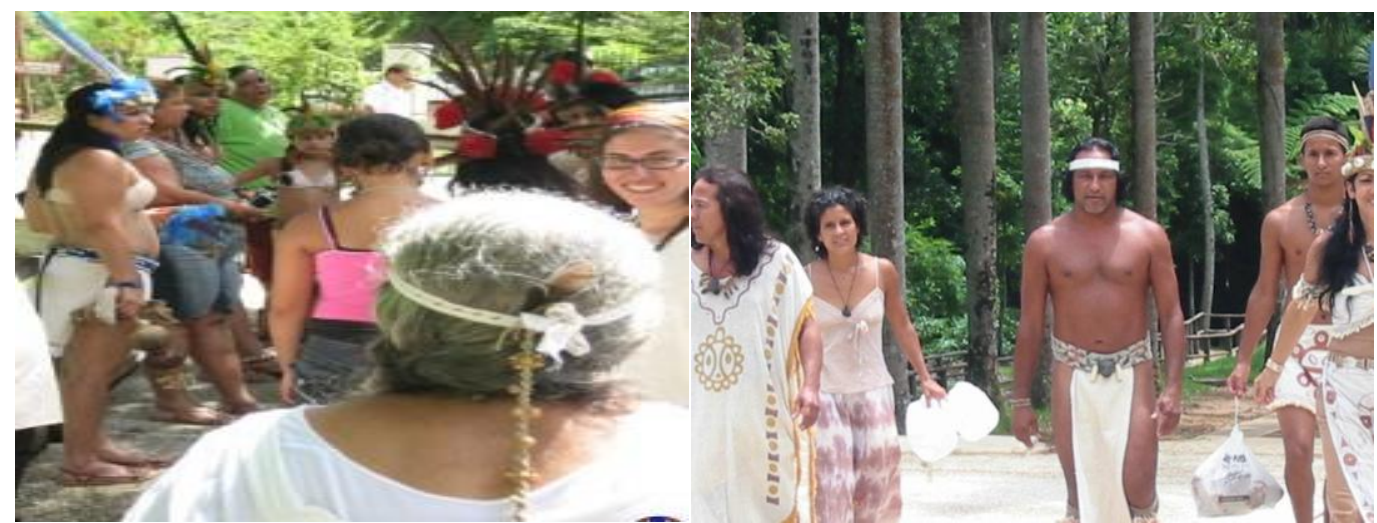

Imág. 1 y 2: Blog. The Voice of the Taino People Online. Aceso en 20/10/2013. Ocupación de los Parques Arqueológicos Nacionales de Puerto Rico.

En esta perspectiva, observamos el actual proceso de construcción de la identidad étnica de los "Neo -Taínos" y comprendemos la necesidad de ampliar el diálogo entre los estudios de patrimonio y la etnoarqueología. El uso de esta herramienta de investigación posibilitará un significativo avance en el conocimiento sobre el grupo en estudio a partir de una mirada interdisciplinar, entre la arqueología, patrimonio, memoria, etnografía, etnoarqueología y la antropología. Como destaca Politis (2002):

En 1991, un profesor de antropología de la Universidad de Bogotá por desconocer la importancia de la etnoarqueología y su especialidad en los estudios actuales con grupos indígenas, "expresó en una reunión de departamento su rechazo hacia la etnoarqueología, pues dijo que no sabía mucho de esta sub-disciplina, pero que no le parecía bién ir a molestar los indios vivos para entender lo que pasaba a los indios muertos "(POLITIS, 2002: 64).

El autor explica también que estas posiciones extremas son incorrectas, debido a que la arqueología como la etnografía, o cualquier otra ciencia antropológica, tiene como uno de sus objetivos principales estudiar la variabilidad de las sociedades humanas y comprender los procesos culturales. Por lo tanto, es del todo correcto estudiar las sociedades actuales para abordar de manera directa y hacer frente a estos fines, o más indirectamente, mediante la identificación de análogos relacionados que sirven para comprender las sociedades del pasado. 
David Kramer (2001) señaló que las múltiples dimensiones de la sociedad humana tienen un papel cada vez mayor en la "Etnoarqueología" moderna. El autor cree que esta subdisciplina opera en la sociedad de los vivos y deben estar sujetas a las mismas normas éticas estrechos de la etnografía contemporánea y no desarrollar cualquier actividad o investigación sin el consentimiento de los actores sociales que se trate (DAVID KRAMER, 2001: 84-89).

Gustavo Politis (2002) observa que algunas investigaciones en curso, cuando recurren a los modelos generados por etnoarqueólogos generalmente se restringen a enfoques y aspectos técnico-económicos de las sociedades del pasado. El autor considera que el enfoque etnoarqueologíco tiene significativamente "mayor potencial que ha sido subvalorado, sobre todo en América del Sur, donde la existencia de una gran variedad de sociedades indígenas y la abundante información etnográfica favorece el desarrollo de esta sub-disciplina"(POLITIS, 2002: 64)

Al referirse a la etnoarqueología Silva (2002) afirma que la relación entre pasado y presente, la estructura y acontecimiento, el mito y la historia, la tradición y la innovación, es una tarea compleja y desafiante que no más se limita, como en los moldes funcionalistas, a pseudoquestiones, como "La pérdida de la Cultura, aculturación o desintegración cultural progresista" (SILVA, 2002a: 9). Para este autor la etnoarqueología es una sub-disciplina que consiste en la comprensión de los artefactos, estructuras y vestigios de otras sociedades en el pasado a través de la utilización de datos etnográficos y históricos, dentro de un contexto cultural bien definido. También considera que los modelos deben comprobarse a través de metodologías etnoarqueológicas propias. Destaca que: En la creación de estos modelos para entender el pasado, "el diálogo con los miembros de las sociedades indígenas y la analogía etnográfica tradicional son herramientas metodológicas poderosas" (SILVA, 2002a: 10).

En este contexto el presente artículo considera indispensable analizar la práctica actual de los "Neo -Taínos" en PR a través de la etnoarqueología la cual posibilita comprender la significación de la dimensión simbólica de sus discursos sobre el patrimonio arqueológico, bien como su relación de pertenencia al área de los parques arqueológicos y la tentativa de construcción de una memoria perdida o la (re)construcción de una memoria "Taíno" no vivida pero, hoy basada y fortificada en informaciones antropológicas, etnográficas y en la cultura material de los Taíno précoloniales. Así buscamos en la etnoarqueología una manera de conocer 
y comprender el modo que los "Neo -Taínos" construyen y (re)construyen su memoria sobre lo patrimonio que reconocen y afirman ser de sus antepasados.

Siendo relevante apuntar que muchas veces los grupos que se reconocen como indígenas en PR se apropian de un patrimonio que probablemente no pertenecía a Taíno précoloniales. Pero, debido a la generalización sobre la historia indígena mencionada por los colonizadores españoles que resume toda la ocupación humana precolonial a una sola clase étnica esto ocurre frecuentemente en el país. Así, los "Neo -Taínos" han establecido una "agency" simbólica que los permite interactuar con los monumentos, los enterramientos indígenas y los artefactos fortaleciendo sus discursos para tener el reconocimiento como los "Verdaderos Taínos" y garantizar sus derechos sobre la tierra donde están situados los sitios arqueológicos, o sea, en los Parques Arqueológicos Nacionales.

En las siguientes imágenes (3 y 4) se puede observar los monumentos arqueológicos presentes en los Parques Nacionales de PR y (5) una reunión del grupo con vestimentas indígena y adornos que consideran Taínos:

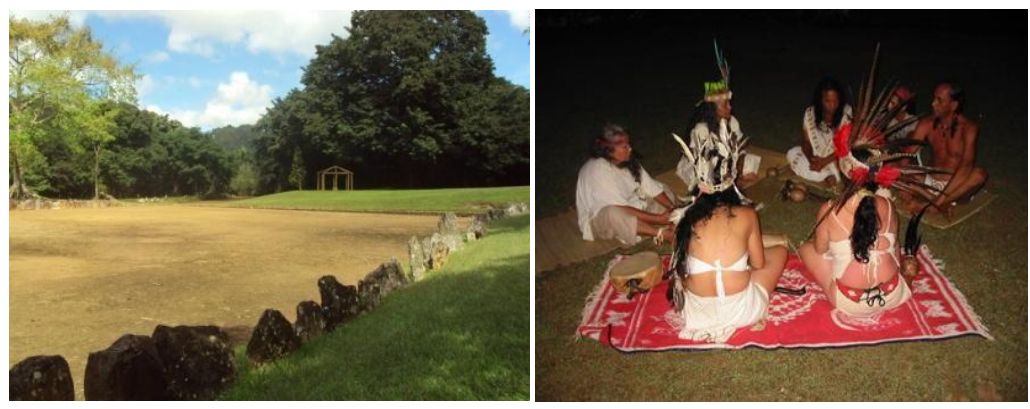

Imág. 3 y 4: Monumentos del Parque Arqueológico de PR. Cristina Burgos /2012. Imág. 5 V: Blog. The Voice of the Taino People Online. Reunión del grupo. Aceso en 20/10/2013.

Estos casos representan un movimiento hacia un supuesto rescate de la vieja manera de ser, las tradiciones reconocido como tribal, por lo "auténtico", sino que aconsejan y apoyan una nueva "Raison d'être" o un nuevo grupo autorizado por las leyes nacionales, indígena" (MOTA, 2008: 23 - apud VIDAL, 2008). Pero, esta ocupación de los sitios arqueológicos en PR en situaciones dificulta hasta el mismo acceso a los sitios, y propicia el saqueo de los hallazgos mediante la apropiación que hacen miembros de estos grupos sobre los recursos arqueológicos considerando de su potestad la protección y uso patrimonial de los mismos. Dichos incidentes 
demuestran la necesidad de un mayor acercamiento entre la ciencia arqueológica, los investigadores, el gobierno y los grupos de interés.

En este sentido consideramos de relevancia establecer un mayor diálogo con grupos de interés como el caso de los "Neo -Taíno" para la continuación de esta propuesta de investigación, creemos que el acercamiento de la comunidad "neo-tribal" hace posible el conocer sus discursos y su relación étnica con el patrimonio en estudio. La intención es conseguir un mayor acceso a los grupos para que en una futura publicación sea posible exponer sus diálogos y interpretación sobre lo parque arqueológico. Así como en este ejercicio escrito, actualmente, muchos arqueólogos/as reconocen la utilidad de la analogía en la argumentación para el proceso de interpretación y explicación del registro arqueológico y que consideramos indispensable. Sin embargo, no todos investigadores/as están convencidos/as de la utilidad de la analogía etnográfica y mecanismos que por lo general se utiliza para su aplicación (GOSDEN, 1999: 9).

Politis (2002) detalla otro punto que ha generado desconfianza entre los investigadores "es que algunas sociedades indígenas que forman las actuales fuentes de analogía están en contacto con la cultura occidental y, de una forma o de otra integrados en el proceso de globalización" (POLITIS, 2002: 62). Debido a esto, en la mayoría de los casos, es cierto que muchos investigadores creen que las sociedades modernas no pueden servir como una referencia analógica de las sociedades del pasado. Politis señala que esta crítica es, sin duda, injustificada porque la investigación etnoarqueologíca opera en los principios de la argumentación analógica y por lo tanto los elementos de similitud (la fuente y el sujeto) no deben ser iguales. Obviamente, cuanto mayor es la similitud entre la fuente y el sujeto, el análogo de argumento tiene un potencial más alto, pero este grado de similitud en sí no asegura la coherencia la veracidad de los argumentos y declaraciones. Desde el punto de vista étnico, la "Etnoarqueología" ha sido cuestionada tanto por los arqueólogos y antropólogos (POLITIS, 2002).

\section{Consideraciones finales}

A lo largo de la realización de este trabajo fue posible observar la insipiente situación de las políticas de gestión del patrimonio arqueológico en PR, también las disputas por reconocimientos étnicos por parte de grupos "Neo -Taíno" que buscan rescatar una memoria 
perdida o no vivida, pero (re)significada a través de los elementos paisajísticos y arqueológicos. La generalización de la historia indígena precolonial de PR a una única categoría étnica, o sea, Taíno por los cronistas y etnógrafos contribuye con los inúmeros equívocos que ocurren en el proceso de identificación de lo patrimonio arqueológico. Siendo necesario una revisión y reorganización del andamiaje que constituye la gestión del patrimonio arqueológico, en específico el de carácter precolonial.

En este caso, la presente investigación propone expandir la mirada para un estudio que destaque las deficiencias e incongruencias del manejo de los recursos arqueológicos. El mismo permitirá desentrañar el complejo de agentes que han modelado la trayectoria de los Parques Nacionales de carácter precolonial y los respectivos usos patrimoniales adjudicados al momento. Lo que permitirá dilucidar una lectura de los bienes culturales y los métodos necesarios para presentarlos al público, de manera que promueva más eficazmente la interpretación de los mismos. Dicha aportación implicará un diagnóstico de la conservación, preservación, mantenimiento, inventario y estado de las colecciones, manifestados en la atención desigual que presentan las agencias responsables por la salvaguardia del patrimonio. Así, elaborar una base para un plan de gestión fundamentado en las necesidades correspondientes de los recursos arqueológicos precoloniales y asegurar su futuro testimonio para las generaciones venideras.

Además de elaborar un plan de manejo para el patrimonio arqueológico de Parques Nacionales de Puerto Rico bajo este carácter, la utilización de las herramientas de la etnoarqueología será indispensable en la continuación de dicho trabajo, bien como contribuirá con las definiciones futuras del proprio plan. La etnoarqueología permitirá también un acercamiento hacia los grupos "Neo-Taíno" permitiendo conocer y comprender más de su cultura y la manera que están interactuando con el contexto arqueológico y construyendo su nueva identidad, bien como los valores simbólicos, religiosos y culturales que agregan a los objetos.

En este sentido, consideramos imposible pensar en el patrimonio arqueológico de los Parques Nacionales de PR, sin echar un vistazo a los discursos de las personas que están interactuando y (re)significando estos espacios, como los "Neo-Taínos". Comprendemos también que hacer un plan de manejo del patrimonio que no contemple el diálogo con la comunidad y los grupos indígenas que viven cerca sería dar continuidad a antiguos trabajos arqueológicos que se dedicaban a las excavaciones omitiendo los vínculos de la cultura material con la gente que la 
produjo y olvidando el rol de la sociedad en la valorización de los bienes patrimoniales (ENDERE, 2010).

De este modo, en su desarrollo, esta investigación contemplará la sociedad y principalmente los grupos de interés, como el caso de los grupos "Neo-Taíno", como "agentes sociales del patrimonio" que adscriben significados a los parques, construyendo una memoria y una nueva mirada sobre los sitios arqueológicos, incentivando una (re)lectura sobre la historia indígena en el país.

\section{Referencias bibliográficas}

ALEGRÍA, Ricardo. Ball Courts and Ceremonial Plazas in the West Indies. Ed. Yale University Publications in Anthropology. New Haven, 1983.

Advisor Council of Historic Preservation National Historic Preservation Act. En: https://www.google.com.br/\#q=Advisory+Council+on+Historic +Preservation+National + Histor ic + Preservation+Act. \&spell=1. Accedido: 12/01/2011.

BALLART J. Y TRESSERRAS, J. Gestión del patrimonio cultural. Ed: Ariel Patrimonio. Barcelona, 2007.

CARRILlO, N. "¿Quién permitió la destrucción del yacimiento de Ponce?". Claridad. 13 de noviembre de 2007.

DAVID, N. \& KRAMER, C. Ethnoarchaeology in Action. Cambridge: Cambridge University Press, 2001.

DE LA LUZ, G. "Taíno as a romantic signifier: Notes on the representation of the "indigenous" in Puerto Rican Archaeology discourse and Ethnohistory". Trabajo presentado en la Asamblea \# 71. Society for American Archaeology. San Juan, 25 al 29 de abril, 2006.

ENDERE, M. L. "Legislación y Manejo de Recursos Culturales". Comunicación en clase, en Curso de Doutorado - UNICEN, Olavarria, 2010.

HASLIP, G. "The politics of Taíno revivalism: The insignificance of Amerindian mtDNA in the population history of Puerto Ricans. A comment on recent research". Centro Journal. 18 (001): 260-275, 2006.

HODDER, I. The Archaeological Process: An introduction. Blackwell Publishers. Oxford. Instituto de Cultura Puertorriqueña (ICP): 2006.

LEY n 183. Ley Orgánica de la Oficina Estatal de Conservación Histórica. Puerto Rico, 2000. 
LEY n 112. Para la Protección del Patrimonio Arqueológico Terrestre. Puerto Rico,1988.

MOTA, Clarice Novaes da. "Ser Indígena no Brasil Contemporâneo: Novos Rumos Para Um Velho Dilema". Revista Ciência e Cultura. Ano 60. n. 4. out., 2008.

"NATIVE AMERICAN GRAVES AND PROTECTION AND REPATRIATION ACT". En: http://www.nps.gov/archeology/tools/laws/NAGPRA.htm. Accedido: 12/01/2011.

PAGÁN, J. "El conocimiento de la arqueología precolombina antillana como motivo social". En: XIX Congreso Internacional de Arqueología del Caribe, Aruba, Indias Occidentales. Del 29 de Junio al 6 de Julio del 2001.

"PLAN ESTATAL DE CONSERVACIÓN HISTÓRICA: Registro Nacional de Lugares Históricos".San Juan. En : http://www2.pr.gov/.../Planificacion/Plan\%20Estatal\%202. Accedido: 10/06/2013.

POLITIS, G. "Acerca de la etnoarqueología en América del Sur". Horizontes Antropológicos. Porto Alegre, ano. 8, n. 18. p. 61-91, 2002.

PAGÁN, J. Y RODRÍGUEZ, R. "Sobre arqueologías de liberación en una colonia postcolonial". Revista de Ciencias Sociales. 19: 8-42, 2008.

PAGÁN, J. "Is all archaeology at present a postcolonial one? Constructive answers from an eccentric point of view". Journal of Social Archaeology. 4(2): 200-213, 2004.En: http://jsa.sagepub.com/content/4/2/200.short. Accedido: 10/05/2012.

"REGLAMENTO DE PROCEDIMIENTOS ADMINISTRATIVOS: Programa de Patrimonio Histórico Edificado, San Juan ICP, 1999". En: http://www.icp.gobierno.pr/Accedido: 12/01/11.

RODRÍGUEZ, A.. "Caguana como ideograma del universo Taíno". Trabajo presentado en el simposio: La observación del cielo y su aportación para la sociedad y cultura en América. LIII Congreso Internacional de Americanistas, Ciudad de México. 19 al 24 de noviembre del 2009.

RODRÍGUEZ LÓPEZ, J. "El Estado: ¿instrumento de destrucción o agente de protección del patrimonio histórico? Algunas reflexiones críticas sobre el caso de Puerto Rico". Cuba Arqueológica. (78) 2: 78-90, 2009.

RODRÍGUEZ, Y. Social life of bateyes: archaeology, preservation and heritage in Puerto Rico. Tesis Doctoral. Graduate Department: Cornell University, NewYork, 2007. 
SEAGEL, P. Ancient Borinquen: archaeology and ethnohistory of native Puerto Rico. University of Alabama Press Servicio Nacional de Parques, 2005.

SILVA, Sergio B. (Org) . "Arqueologia e Sociedades Tradicionais". Horizontes Antropológicos. Porto Alegre, ano. 8, n.18. p. 7-10, 2002.

SKEATES, R. Debating the archaeological heritage. Ed: Gerald Duckworth. London. 2000.

SMITH, L. "The Repatriation of human remains: a problem or opportunity". Antiquity. 78: 404413, 2004.

"THE CASE OF TAÍNO: History and Heritage". Journal Claridad, 2008. En:http://www.claridadpuertorico.com. Accedido:20/10/2012.

TRIGGER, B. "Alternative Archaeology: Nationalist, Colonialist and Imperialist". En: Contemporary Archaeology in Theory. A Reader. Eds. R. Preucel and I. Hodder. Blackwell, pp: 615-631. Oxford, 1996.

TRIGGER, B. "Alternative archaeologies in historical perspective". En: Evaluating Multiple Narratives Beyond Nationalist, Colonialist, Imperialist Archaeologies. Eds: J. Habu, C. Fawcett y J. Matsunaga, pp: 187-196 Springer Science Business Media, LLC. New York, $2008 .$.

VIDAL, Pouey Viviane. "Etnoarqueologia dos Charrua do Presente: A Boleadeira como Patrimônio Simbólico na Construção de Identidades". In: Encontro Regional Sul da Sociedade de Arqueologia Brasileira. Região Sul/SAB-Sul, 2008.

WENBAN-SMITH. F. "Square pegs in round holes: problems of managing the Paleolithic heritage". En: Managing archaeology. Ed: M.A. Cooper, A. Firth, J. Carman, y D. Wheatley, pp: 146-160. Routledge, London, 1995. 